\title{
THE ROLE OF CALCIUM SIGNALLING IN THE CHONDROGENIC RESPONSE OF MESENCHYMAL STEM CELLS TO HYDROSTATIC PRESSURE
}

\author{
A.J. Steward ${ }^{1,2}$, D.J. Kelly ${ }^{2,3,4}$ and D.R. Wagner ${ }^{1, *}$ \\ ${ }^{1}$ Bioengineering Graduate Program, Department of Aerospace and Mechanical Engineering, \\ University of Notre Dame, Notre Dame, IN, USA \\ ${ }^{2}$ Trinity Centre for Bioengineering, Trinity Biomedical Sciences Institute, Trinity College Dublin, Dublin, Ireland \\ ${ }^{3}$ Department of Mechanical and Manufacturing Engineering, School of Engineering, Trinity College Dublin, \\ Dublin, Ireland \\ ${ }^{4}$ Advanced Materials and Bioengineering Research Centre (AMBER), Trinity College Dublin, Dublin, Ireland
}

\begin{abstract}
The objective of this study was to elucidate the role of calcium $\left(\mathrm{Ca}^{++}\right)$signalling in the chondrogenic response of mesenchymal stem cells (MSCs) to hydrostatic pressure (HP). MSCs were seeded into agarose hydrogels, subjected to HP or kept in free swelling conditions, and cultured either with or without pharmacological inhibitors of $\mathrm{Ca}^{++}$ mobility and downstream targets. Chelating free $\mathrm{Ca}^{++}$, inhibiting voltage-gated calcium channels, and depleting intracellular calcium stores suppressed the beneficial effect of $\mathrm{HP}$ on chondrogenesis, indicating that $\mathrm{Ca}^{++}$mobility may play an important role in the mechanotransduction of HP. However, inhibition of stretch-activated calcium channels in the current experiment yielded similar results to the control group, suggesting that mechanotransduction of HP is distinct from loads that generate cell deformations. Inhibition of the downstream targets calmodulin, calmodulin kinase II, and calcineurin all knocked down the effect of HP on chondrogenesis, implicating these targets in MSCs response to HP. All of the pharmacological inhibitors that abolished the chondrogenic response to HP also maintained a punctate vimentin organisation in the presence of HP, as opposed to the mechanoresponsive groups where the vimentin structure became more diffuse. These results suggest that $\mathrm{Ca}^{++}$signalling may transduce HP via vimentin adaptation to loading.
\end{abstract}

Keywords: Calcium signalling, vimentin, hydrostatic pressure, mesenchymal stem cells, chondrogenesis.

\footnotetext{
*Address for correspondence:

Diane R. Wagner, PhD

Department of Aerospace and Mechanical Engineering 145 Multidisciplinary Research Building

University of Notre Dame, Notre Dame

IN 46556, USA
}

Telephone Number: 1574 631-5735

FAX Number: 1 574-631-2144

E-mail: dwagner@nd.edu

\section{Introduction}

Mechanical cues play a key role in mesenchymal stem cell (MSC) differentiation (Discher et al., 2009; Kelly and Jacobs, 2010; McBeath et al., 2004; Steward et al., 2011; Thorpe et al., 2012). The response to such cues strongly depends on the type (i.e. compression, fluid flow, tension, hydrostatic pressure), frequency, magnitude, and duration of loading (Kelly and Jacobs, 2010; Meyer et al., 2011; Miyanishi et al., 2006b; Steward et al., 2013b). Fluid pressurisation is the dominant load-bearing mechanism of cartilage, supporting up to $90 \%$ of the compressive load in the in vivo joint environment (Park et al., 2003). In accordance with its prominence in cartilaginous tissues, hydrostatic pressure (HP) is an important regulator of chondrogenic differentiation of MSCs, increasing chondrogenic gene expression and matrix production, and also suppressing markers of hypertrophy (Angele et al., 2003; Carroll et al., 2014; Luo and Seedhom, 2007; Meyer et al., 2011; Miyanishi et al., 2006a; Miyanishi et al., 2006b; Ogawa et al., 2009; Steward et al., 2012; Steward et al., 2013a; Vinardell et al., 2012; Wagner et al., 2008; Wong et al., 2003). Mechanotransduction of HP has been proposed to differ from other mechanical loads due to the fact that HP generates a state of stress with little deformation (Elder and Athanasiou, 2009), as hydrated tissues and cells are nearly incompressible. However, surprisingly little is known about the mechanisms by which cells sense and respond to HP.

Recently, we demonstrated that integrin binding to the pericellular matrix regulates vimentin organisation in MSCs and determines their response to cyclic HP (Steward et al., 2013a). Another proposed element of HP mechanotransduction is fluctuations in intracellular ion concentrations, which are altered by the application of HP (Browning et al., 2004; Hall, 1999; Mizuno, 2005). In particular, calcium ion $\left(\mathrm{Ca}^{++}\right)$signalling has been implicated as a critical regulator of cellular response in other mechanical loading modalities, yet no studies have examined the role of $\mathrm{Ca}^{++}$signalling in the response of MSCs to HP. $\mathrm{Ca}^{++}$signalling is complex and involves a variety of channels, receptors and secondary messengers (Fig. 1). Stretch activated calcium channels (SACCs) have been demonstrated to be required for mechanotransduction of a variety of loading types in chondrocytes and MSCs (McMahon et al., 2008; Mizuno, 2005; Mobasheri et al., 2002; Wright et al., 1996). Voltage gated calcium channels (VGCCs) are activated by membrane depolarisation and 


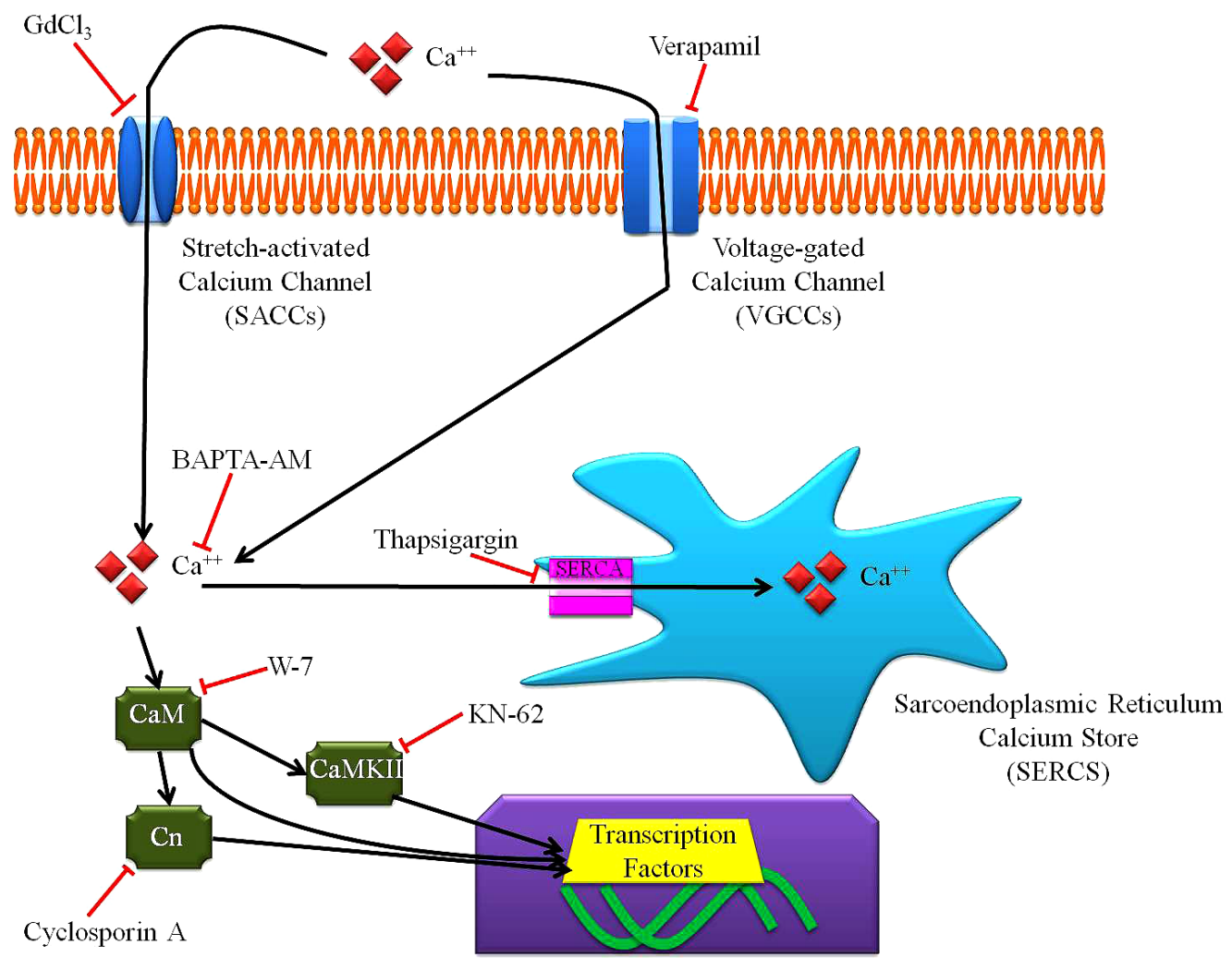

Fig. 1. The calcium signalling pathways examined and the inhibitors utilised in the current study.

mediate $\mathrm{Ca}^{++}$influx (Catterall, 2011). $\mathrm{Ca}^{++}$influx via SACCs and/or VGCCs increases $\mathrm{Ca}^{++}$concentrations directly and also indirectly through calcium-induced calcium release via calcium-sensitive receptors in the sarcoendoplasmic reticulum calcium stores (SERCS) (Catterall, 2011). VGCCs and SERCS were both found to be required for chondrogenesis in high-density chicken MSCs culture (Fodor et al., 2013), and they have both been implicated in mechanotransductive pathways (Riddle et al., 2006; Shakibaei and Mobasheri, 2003; Valhmu and Raia, 2002). Finally, $\mathrm{Ca}^{++}$utilises secondary messengers, such as calmodulin (CaM), calmodulin kinase type II (CaMKII) and calcineurin $(\mathrm{Cn})$, which subsequently initiate a variety of signalling cascades. CaM, CaMKII and $\mathrm{Cn}$ have been implicated in mechanotransduction of fluid flow and compression in MSCs as well as chondrocytes (Riddle et al., 2006; Valhmu and Raia, 2002).

While intracellular $\mathrm{Ca}^{++}$concentrations are known to increase in chondrogenic cells after application of HP (Mizuno, 2005), the effects of this increase on the chondrogenesis of MSCs and the specific channels and downstream effectors utilised by MSCs to sense and respond to HP are unknown. Further, integrins, the cytoskeleton, and $\mathrm{Ca}^{++}$channels have previously been proposed to interact with one another (Erickson et al., 2003; Lee et al., 2000; Mobasheri et al., 2002; Shakibaei and Mobasheri, 2003; Wright et al., 1997), thus recent findings that integrin binding and cytoskeletal organisation regulate the mechanotransduction of HP implicate a possible role for $\mathrm{Ca}^{++}$signalling in mediating this process. Therefore, in order to elucidate the role of $\mathrm{Ca}^{++}$signalling in the mechanotransduction of HP, chondrogenic matrix accumulation, focal adhesion formation and cytoskeletal organisation were examined in MSCs exposed to HP in the presence of pharmacological inhibitors of $\mathrm{Ca}^{++}$mobility and downstream signalling molecules.

\section{Materials and Methods}

\section{Cell isolation, expansion and encapsulation}

Femora from 6-month-old pigs ( $50 \mathrm{~kg})$ were procured from a local abattoir (Martin's Custom Butchering, Wakarusa, IN, USA) and the bone marrow was harvested from the diaphysis within $3 \mathrm{~h}$ of slaughter under sterile conditions. MSCs were isolated and expanded according to a modified method developed for human MSCs (Lennon and Caplan, 2006). Briefly, bone marrow was removed from the femur, washed and centrifuged twice, and sieved through a $40 \mu \mathrm{m}$ pore-size cell sieve (Falcon, VWR, Batavia, IL, USA). The remaining cell suspension was counted by trypan blue exclusion and seeded at a density of $80 \times 10^{6}$ cells per $75 \mathrm{~cm}^{2}$ T-flask in a humidified atmosphere of $37^{\circ} \mathrm{C}$ and $5 \% \mathrm{CO}_{2}$. Non-adherent cells were removed after $3 \mathrm{~d}$ in culture. At each passage, cells were reseeded at a density of 875,000 cells per $175 \mathrm{~cm}^{2}$ T-flask. Cultures were expanded in high-glucose Dulbecco's modified Eagle's Medium (hgDMEM GlutaMAX; Gibco, Life Technologies, Grand Island, NY, USA) supplemented with $10 \%$ foetal bovine serum (FBS; Omega Scientific, Tarzana, CA, USA), and penicillin (100 U/mL)-streptomycin $(100 \mu \mathrm{g} /$ $\mathrm{mL}$ ) (Corning, VWR). After expansion (third passage) MSCs were encapsulated in agarose (Type VII, SigmaAldrich, St. Louis, MO, USA) at a density of $15 \times 10^{6}$ cells $/ \mathrm{mL}$. Briefly, MSCs were mixed with $5 \%$ agarose 

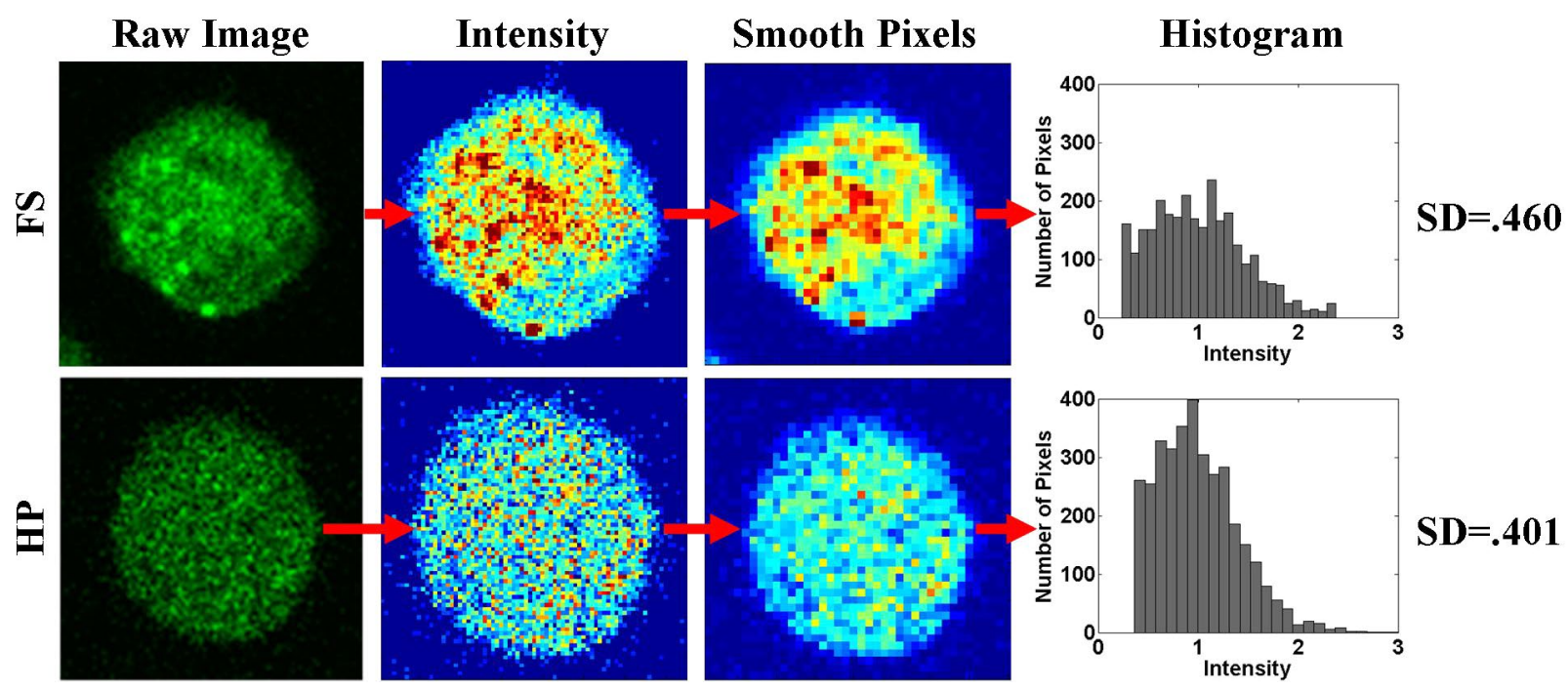

$\mathrm{SD}=\mathbf{. 4 0 1}$

Fig. 2. A custom MATLAB code converted raw confocal images of vimentin structure to images of pixel intensity and subsequently averaged over a 2 x 2 grid of pixels to smooth the image. Finally, a distribution of intensities within each cell was plotted and the standard deviation was used as a measure of homogeneity within each cell.

at $\sim 40{ }^{\circ} \mathrm{C}$ to yield a final gel concentration of $4 \%$. The agarose-cell suspension was cast in a stainless steel mould, and cored using biopsy punches to produce cylindrical scaffolds (Ø 5 × $3 \mathrm{~mm}$ thickness). Constructs were maintained in $2.5 \mathrm{~mL} /$ construct of a chemically defined medium consisting of hgDMEM GlutaMAX supplemented with penicillin $(100 \mathrm{U} / \mathrm{mL})$-streptomycin $(100 \mu \mathrm{g} / \mathrm{mL})$, $100 \mu \mathrm{g} / \mathrm{mL}$ sodium pyruvate (Lonza, VWR), $40 \mu \mathrm{g} / \mathrm{mL}$ L-proline (Sigma-Aldrich), $50 \mu \mathrm{g} / \mathrm{mL}$ L-ascorbic acid2-phosphate (Sigma-Aldrich), $1.5 \mathrm{mg} / \mathrm{mL}$ bovine serum albumin (BSA, Fisher Scientific, Pittsburgh, PA, USA), 1 $\mathrm{x}$ insulin-transferrin-selenium (Gibco, Life Technologies), $100 \mathrm{nM}$ dexamethasone (Sigma-Aldrich) and $10 \mathrm{ng} /$ $\mathrm{mL}$ recombinant human transforming growth factor- $\beta 3$ (TGF- $\beta 3$; PeproTech, Rocky Hill, NJ, USA). In order to inhibit $\mathrm{Ca}^{++}$mobility, constructs were incubated with either $5 \mu \mathrm{M}$ BAPTA-AM (an intracellular calcium chelator, $-\mathrm{Ca}^{++}$; Valhmu and Raia, 2002), $10 \mu \mathrm{M} \mathrm{GdCl}_{3}$ (inhibits stretchactivated calcium channels, -SACC; McMahon et al., 2008), $10 \mu \mathrm{M}$ verapamil (inhibits voltage-gated calcium channels, -VGCC; Hung et al., 1996a), $50 \mathrm{nM}$ thapsigargin (depletes sarco/endoplasmic reticulum calcium stores, -SERCS; Yellowley et al., 1997) (all Sigma-Aldrich), or without any pharmacological inhibitors as a control (Ctrl). In a second experiment, the role of downstream targets of $\mathrm{Ca}^{++}$signalling was investigated with either $5 \mu \mathrm{M} \mathrm{W}-7$ (inhibits calmodulin, -CaM; Xu et al., 2009), $10 \mu \mathrm{M} \mathrm{KN}-62$ (inhibits calmodulin kinase type II, -CaMKII; Szabo et al., 2009), or $3.5 \mu \mathrm{M}$ cyclosporine A (inhibits calcineurin, -Cn; Tomita et al., 2002) (all Sigma-Aldrich). Constructs were allowed to equilibrate overnight before the initiation of hydrostatic pressure. The constructs were cultured with the relevant pharmacological inhibitor (or without inhibitors in the control groups) for the duration of the experiment.

\section{Application of hydrostatic pressure}

Constructs $(n=9)$ were sealed into sterile bags with $1.5 \mathrm{~mL}$ of medium per construct during the daily loading period. After loading, constructs were removed from bags and returned to culture dishes containing $2.5 \mathrm{~mL}$ of medium per construct to allow gases to equilibrate overnight. Cyclic HP was applied in a cell disruption bomb (Parr Instrument Company, Moline, IL, USA) filled with water within a $37^{\circ} \mathrm{C}$ water bath as described previously (Meyer et al., 2011). The sealed bags exposed to HP were placed into the pressure vessel while the free swelling (FS) controls were placed in a separate pressure vessel, which was immersed in the same temperature-regulated water bath but was not connected to the mechanical testing system. The pressure vessel was connected to a hydraulic cylinder (PHD, Inc., Fort Wayne, IN, USA) that was loaded using a computer controlled Instron 88215 materials testing machine. The pressure inside the vessel was measured using a pressure gauge (McMaster-Carr, Princeton, NJ, USA). The load applied to the hydraulic cylinder by the Instron was such that the HP inside the vessel reached an amplitude of $10 \mathrm{MPa}$ at a frequency of $1 \mathrm{~Hz}, 4 \mathrm{~h} / \mathrm{d}, 5 \mathrm{~d} /$ week for 3 weeks. Half-medium exchanges were performed every 3-4 d to replenish nutrients and pharmacological inhibitors, and media samples were collected for biochemical analysis on day 21.

\section{Biochemical analysis}

On day 21 constructs $(n=4)$ were digested with papain $(125 \mu \mathrm{g} / \mathrm{mL})$ in $0.1 \mathrm{M}$ sodium acetate, $5 \mathrm{mM}$ L-cysteine$\mathrm{HCl}$, and 0.05 M EDTA (pH 6.0, all Sigma-Aldrich) at $60{ }^{\circ} \mathrm{C}$ under constant rotation for $18 \mathrm{~h}$. The PicoGreen assay (Life Technologies) was used to quantify DNA content. Sulphated glycosaminoglycan (sGAG) content was quantified using a modified dimethylmethylene blue (DMMB) dye-binding assay with a chondroitin sulphate standard. Briefly, aliquots of the papain digest were mixed with a dye solution consisting of $80 \mu \mathrm{M}$ DMMB (SigmaAldrich), $1 \%$ ethanol (Acros Organics, VWR), $40 \mathrm{mM}$ guanidine- $\mathrm{HCl}$ (Calbiochem, VWR), $315 \mu \mathrm{M}$ formic acid, and $25 \mu \mathrm{M}$ sodium hydroxide (Sigma-Aldrich) at a $\mathrm{pH}$ of 3.5 for $30 \mathrm{~min}$ and then centrifuged. The supernatant was removed and the remaining pellet was resuspended in a 
a

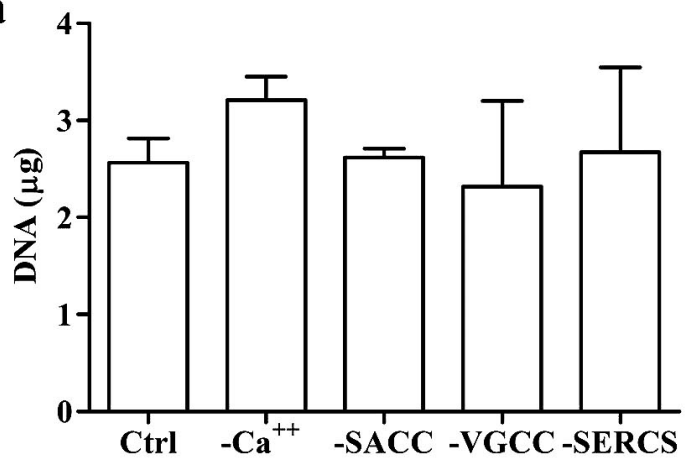

b

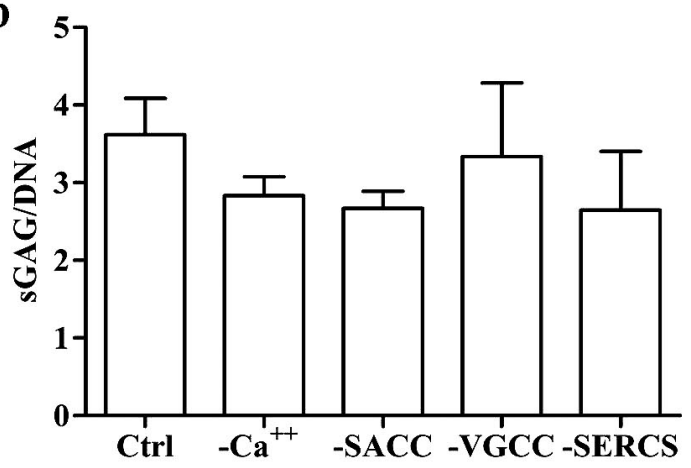

Fig. 3. (a) DNA and (b) sGAG/DNA in free-swelling constructs exposed to various calcium signalling inhibitors. a: $p \leq 0.05$, relative to control.
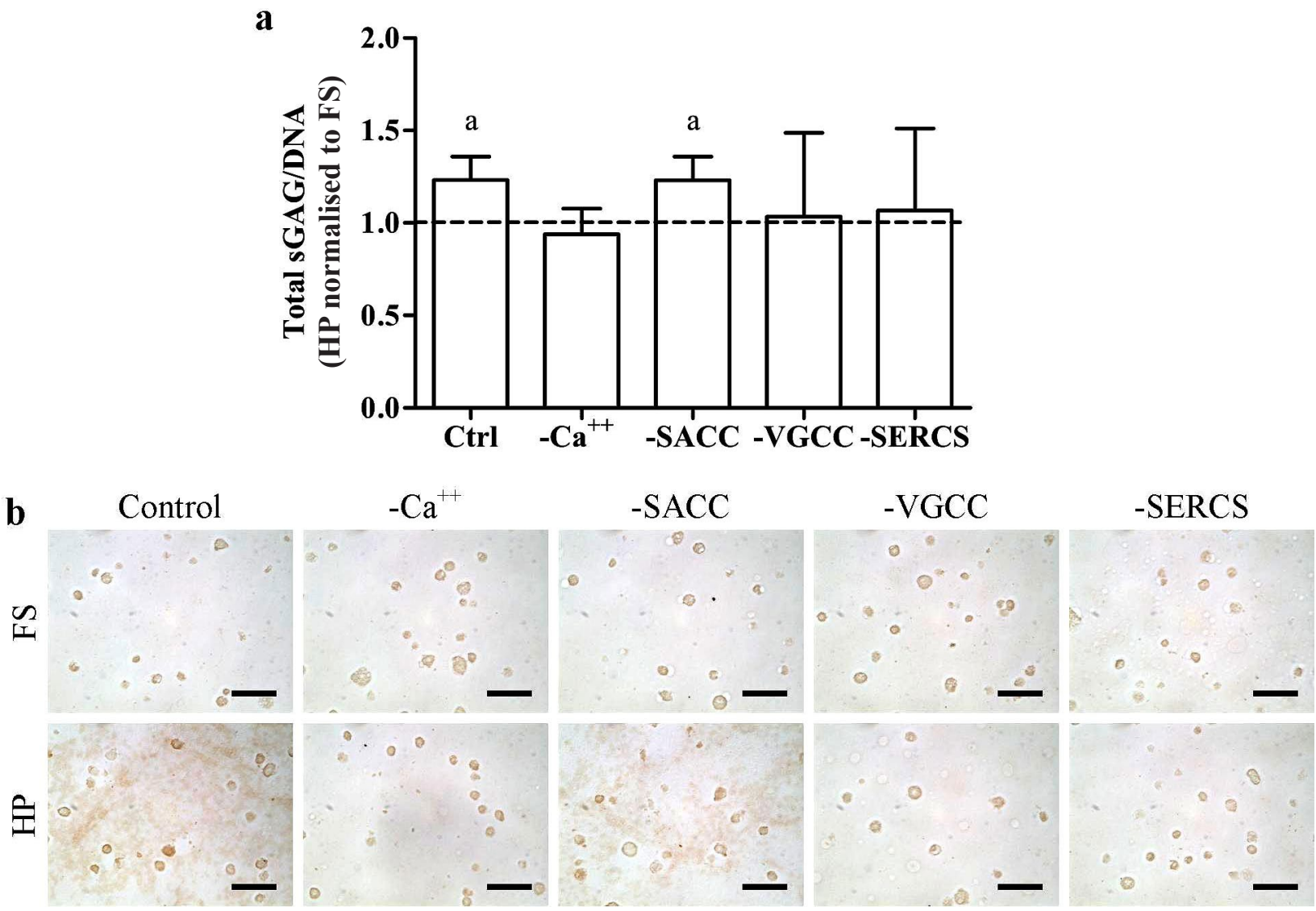

Fig. 4. (a) Total sGAG/DNA normalised to the FS condition. (b) Representative collagen type II immunohistological images. Scale bars $=50 \mu \mathrm{m}$. a: $p<0.05$, relative to FS condition.

dissociation buffer of $10 \%$ isopropanol (Alfa Aesar, VWR) and $4 \mathrm{M}$ guanidine- $\mathrm{HCl}$ (Calbiochem, VWR). The resultant solution was measured colourimetrically at $600 \mathrm{~nm}$. Media samples were also analysed for sGAG content using the modified DMMB assay, and subsequently added to that accumulated within constructs to yield the total sGAG produced. Total sGAG/DNA values from the HP groups were normalised to the FS groups when applicable. All assays were performed in triplicate.

\section{Confocal microscopy and immunohistochemistry}

At day 21, constructs $(n=2)$ were cut in half and fixed in $4 \%$ paraformaldehyde (Fisher Scientific) overnight at $4{ }^{\circ} \mathrm{C}$ and rinsed with phosphate-buffered saline (PBS). In order to examine focal adhesion formation and cytoskeletal organisation, samples were permeabilised in a $1 \%$
Triton-X and $2 \%$ BSA solution for $45 \mathrm{~min}$ and washed in PBS. The samples were then incubated in a $1.5 \%$ BSA solution containing one of either $60 \mu \mathrm{g} / \mathrm{mL}$ monoclonal anti-vinculin FITC conjugate (Sigma-Aldrich), $5 \mathrm{U} / \mathrm{mL}$ rhodamine phalloidin (VWR), $1 \mu \mathrm{g} / \mathrm{mL}$ anti-vimentin FITC (eBioscience, Inc., San Diego, CA, USA), or $1 \mu \mathrm{g} /$ $\mathrm{mL}$ anti-alpha tubulin eFluor $^{\circledR} 615$ (eBioscience, Inc.) for $1.5 \mathrm{~h}$, and then imaged using a Nikon A1R confocal microscope at $40 \mathrm{x}$ magnification.

A custom code (MATLAB R2013a, The Mathworks, Inc., Natick, MA, USA) was developed in order to analyse the confocal images semi-quantitatively (Fig. 2). All cells in the plane of view of at least five representative images were selected in MATLAB and converted to an image of pixel intensity. Then, the intensities of $2 \times 2$ pixel squares $(0.6 \times 0.6 \mu \mathrm{m})$ were averaged in order to smooth the 


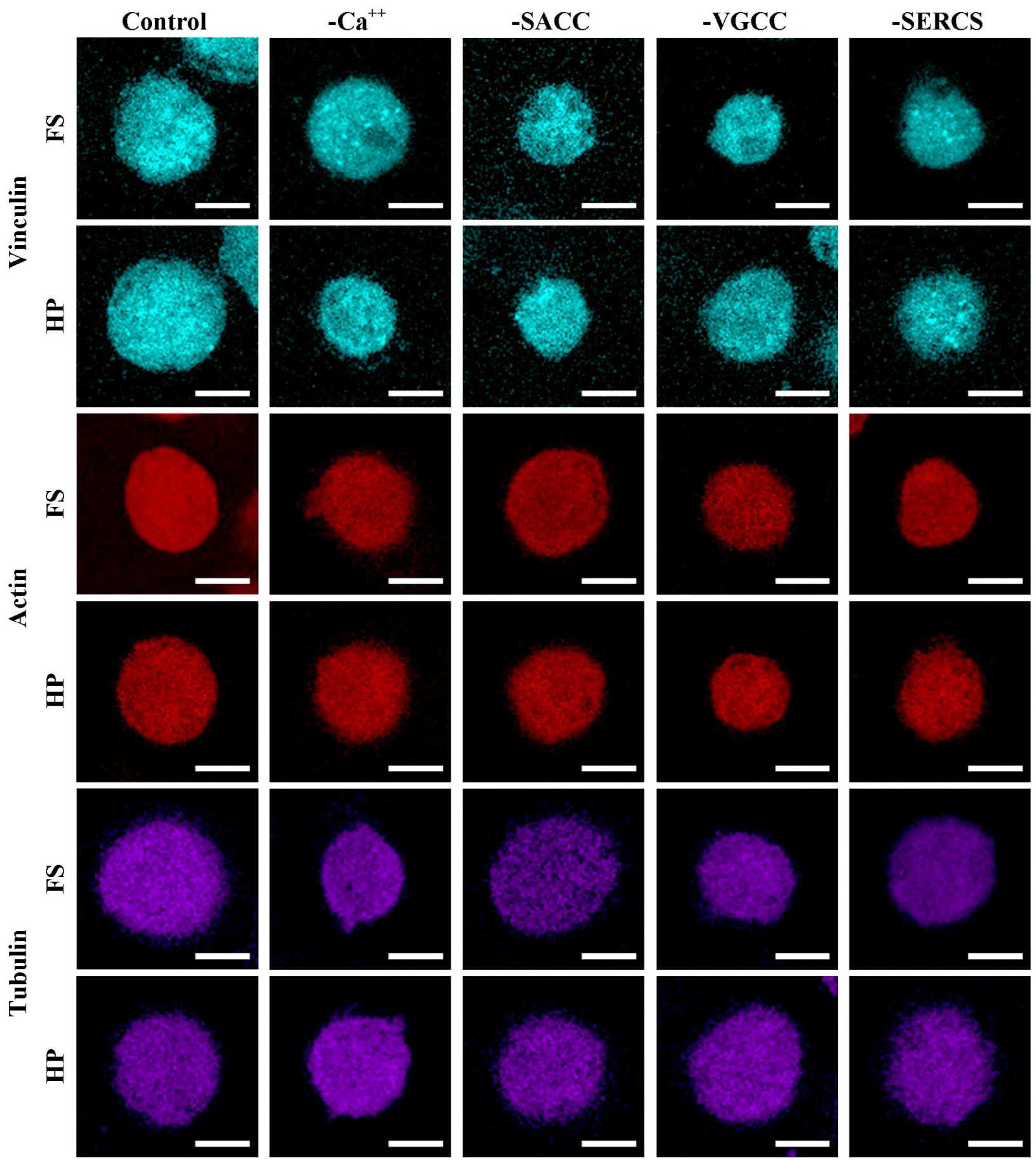

Fig. 5. Representative confocal images of vinculin, actin and tubulin staining of constructs in either the HP or FS groups. Scale bars $=10 \mu \mathrm{m}$.

image. Next, all non-zero intensity values were compiled and the intensity of each square was normalised to the mean intensity of the given image. Finally, the standard deviation of the intensities was found as a measure of the homogeneity of the cytoskeletal architecture. These standard deviations were then averaged across multiple cells from each group $(27 \leq n \leq 48)$. Finally, the number of cells that had punctate or diffuse vimentin architecture was visually determined in the control HP and FS groups.

The remaining halves were dehydrated and embedded in paraffin wax. Constructs were sectioned perpendicular to the disc face yielding $5 \mu \mathrm{m}$ thick sections. Collagen type II was then identified through immunohistochemistry.
Sections were treated with peroxidase, followed by chondroitinase ABC (Sigma-Aldrich) in a humidified environment at $37^{\circ} \mathrm{C}$ for $1 \mathrm{~h}$ to permeabilise the extracellular matrix. Samples were then blocked with goat serum, and afterwards the primary antibody for collagen type II (mouse monoclonal, Abcam, Cambridge, MA, USA) was applied for $1 \mathrm{~h}$. Next, the secondary antibody (anti-mouse IgG biotin conjugate, Sigma-Aldrich) was added for $1 \mathrm{~h}$ followed by incubation with $\mathrm{ABC}$ reagent (Thermo Scientific, VWR) for $45 \mathrm{~min}$. Finally, the slides were developed with DAB peroxidase (Thermo Scientific, VWR) for $5 \mathrm{~min}$. Samples were washed with PBS between each step. 

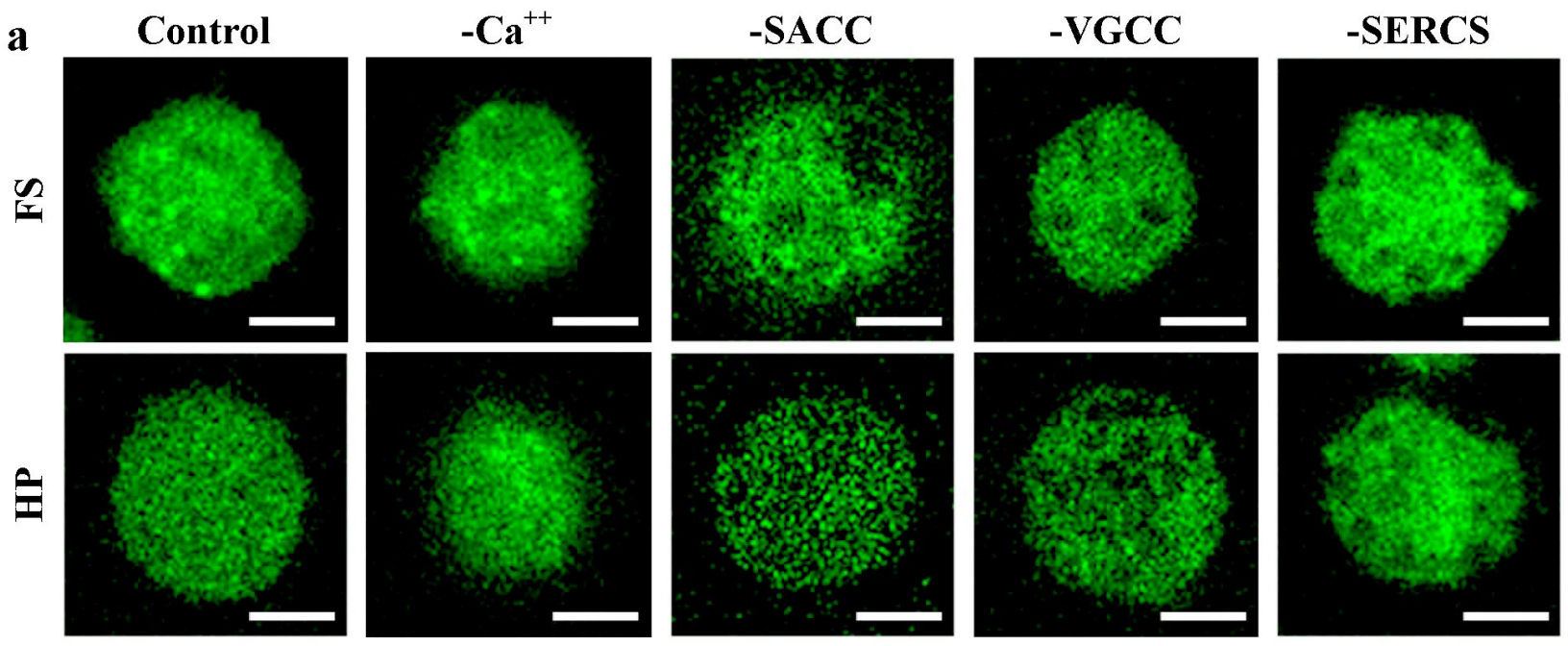

b

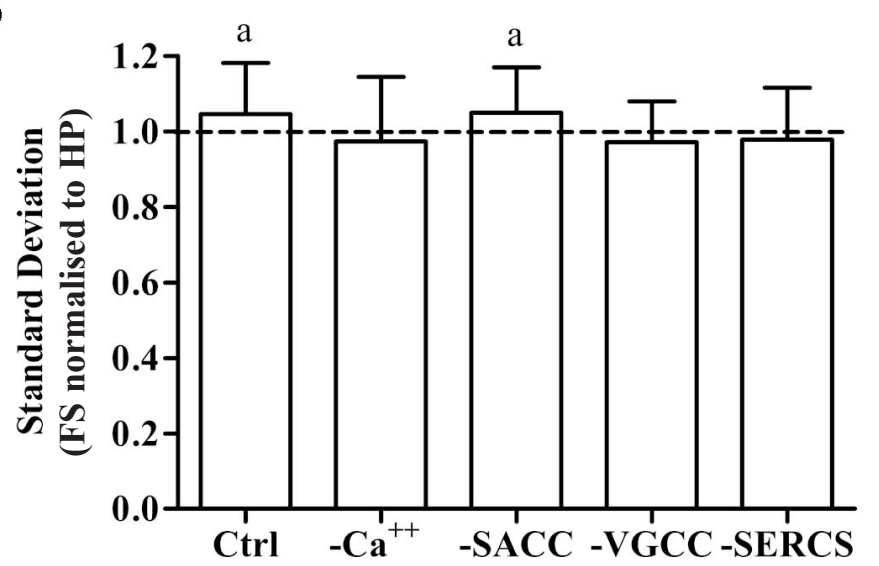

Fig. 6. (a) Representative confocal images of vimentin in constructs in either the HP or FS groups. (b) Semi-quantitative analysis using custom MATLAB code to determine differences in vimentin structures in FS constructs normalised to those exposed to HP. Scale bars $=10 \mu \mathrm{m}$. a: $p \leq 0.05$, relative to HP condition.

\section{Statistical analysis}

Statistical analysis was performed using Prism (version 4.03, GraphPad Software, La Jolla, CA, USA). Biochemical results, both numerical and graphical, are expressed in the form of mean \pm standard deviation. Differences between HP and FS samples were determined using a Student's $t$-test, while differences between groups cultured with or without the various inhibitors tested were determined using a one-way ANOVA with Bonferroni post-test. A level of $p<0.05$ was considered significant.

\section{Results}

\section{$\mathrm{Ca}^{++}$mobility may be a key regulator of the} mechanotransduction of HP

Previous work has demonstrated that porcine bone marrow-derived MSCs remain viable in agarose hydrogels for up to $42 \mathrm{~d}$ (Thorpe et al., 2008; Thorpe et al., 2010), and we have observed $90 \%$ DNA content on day 21 as compared to day 0 , on average, during several of our previous experiments (data not shown). Additionally, we have previously reported that HP does not alter the DNA quantity of MSC-seeded agarose constructs after $21 \mathrm{~d}$ of loading (Steward et al., 2012). To determine whether the DNA content is altered by the presence of pharmacological inhibition of $\mathrm{Ca}^{++}$mobility, DNA in the free-swelling Ctrl, $-\mathrm{Ca}^{++}$, -SACC, -VGCC and -SERCS constructs from the first experiment was quantified at day 21 . None of the inhibitors had a significant effect on the DNA levels (Fig. 3a). Additionally, the quantity of sGAG/DNA was also not significantly different between the different groups (Fig. $3 b)$, suggesting that chondrogenic differentiation was not altered by the addition of the inhibitors.

In the control specimens, HP significantly enhanced sGAG synthesis by $23 \%$ (Fig. 4a), and also increased collagen type II immunostaining (Fig. 4b). Interestingly, inhibition of $\mathrm{Ca}^{++}$signalling with an intracellular calcium chelator $\left(-\mathrm{Ca}^{++}\right)$suppressed the beneficial effect of HP on sGAG production and collagen type II accumulation (Fig. 4a,b). Next, SACCs, VGCCs and SERCS were suppressed in order to determine how $\mathrm{Ca}^{++}$signalling was being initiated by HP. Hindering SACC activity did not negate the beneficial effects of HP on sGAG accumulation or collagen type II deposition; however, inhibition of both VGCCs and SERCS abrogated the mechanoresponse of MSCs to HP (Fig. 4a,b). 
a

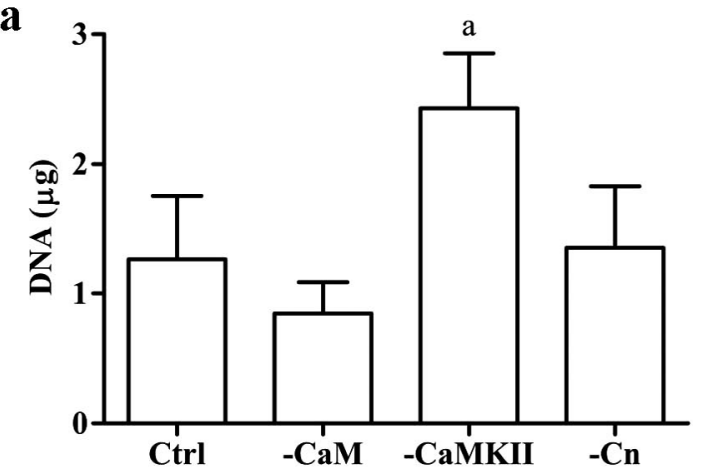

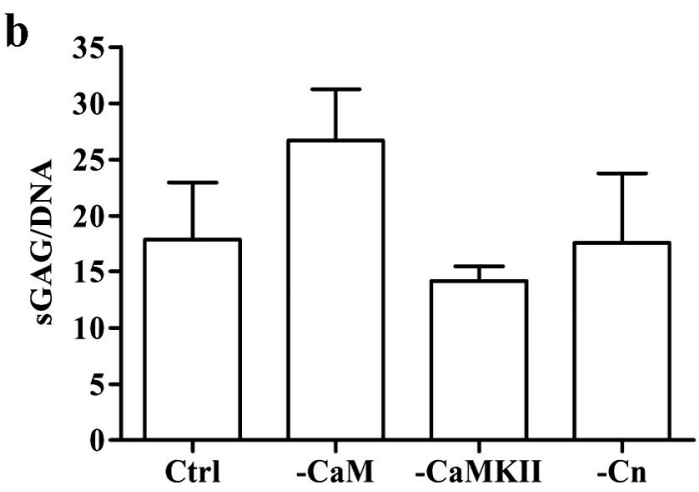

Fig. 7. (a) DNA and (b) sGAG/DNA in free-swelling constructs exposed to various inhibitors of downstream calcium targets. a: $p \leq 0.05$, relative to control.

a
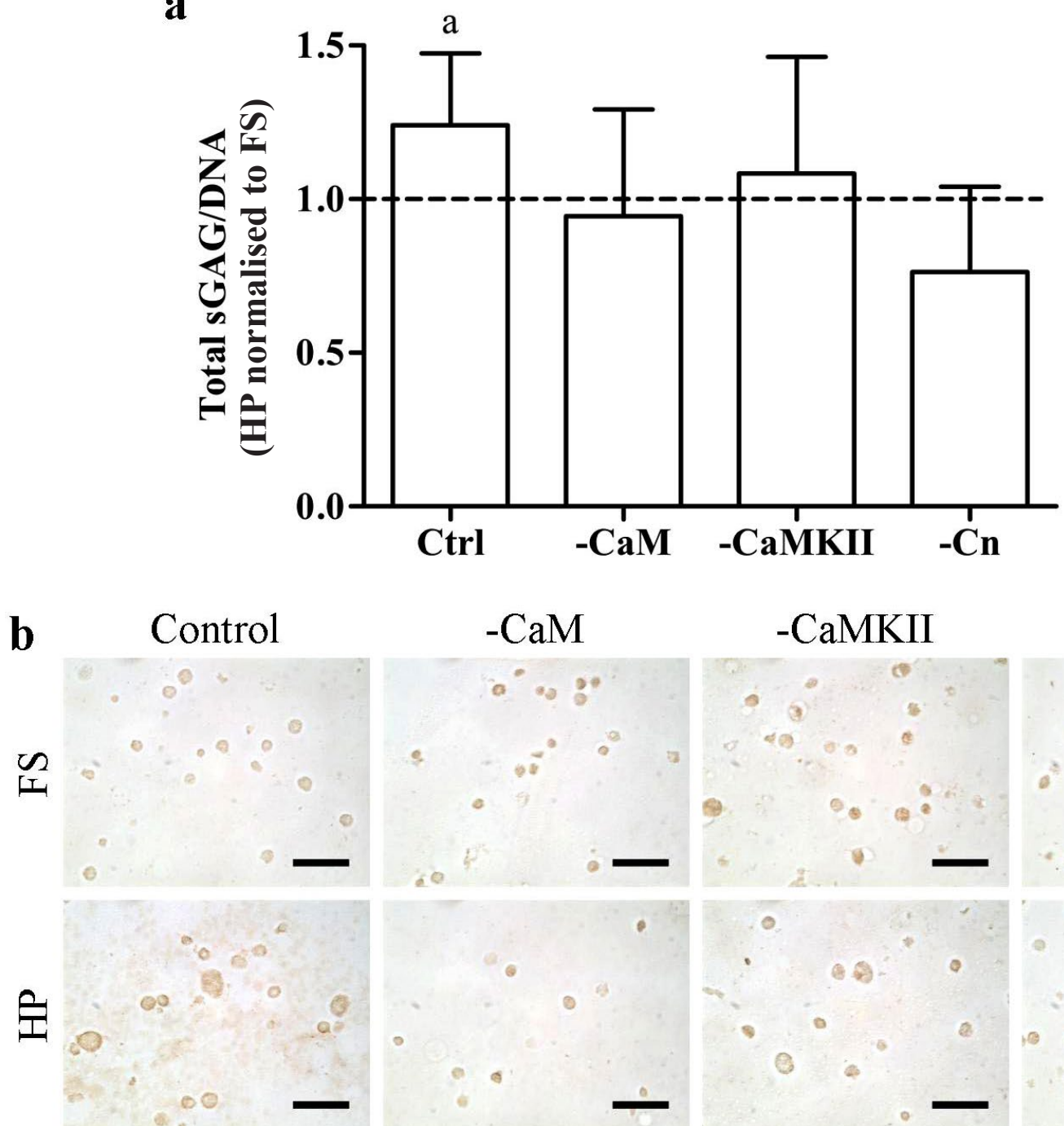

Fig. 8. (a) Total sGAG/DNA normalised to the FS condition. (b) Representative collagen type II immunohistological images. Scale bars $=50 \mu \mathrm{m}$. a: $p<0.05$, relative to FS condition.

$\mathrm{Ca}^{++}$mobility may be required for changes in vimentin architecture in response to $\mathrm{HP}$

Focal adhesion formation was previously determined to be necessary for mechanotransduction of HP (Steward et al., 2013a). Therefore, focal adhesions were next examined with confocal microscopy in order to determine if inhibition of $\mathrm{Ca}^{++}$mobility was regulating the mechanoresponse of MSCs to HP via alterations in focal adhesion formation.
Neither the pharmacological inhibitors nor application of HP affected focal adhesion formation, with all groups demonstrating a punctate structure (Fig. 5).

The cytoskeleton has long been implicated in mechanotransduction, yet no changes were observed in actin or tubulin structure with either inhibition of $\mathrm{Ca}^{++}$ mobility or application of HP (Fig. 5). However, exposure to HP led to a more diffuse vimentin structure in the 


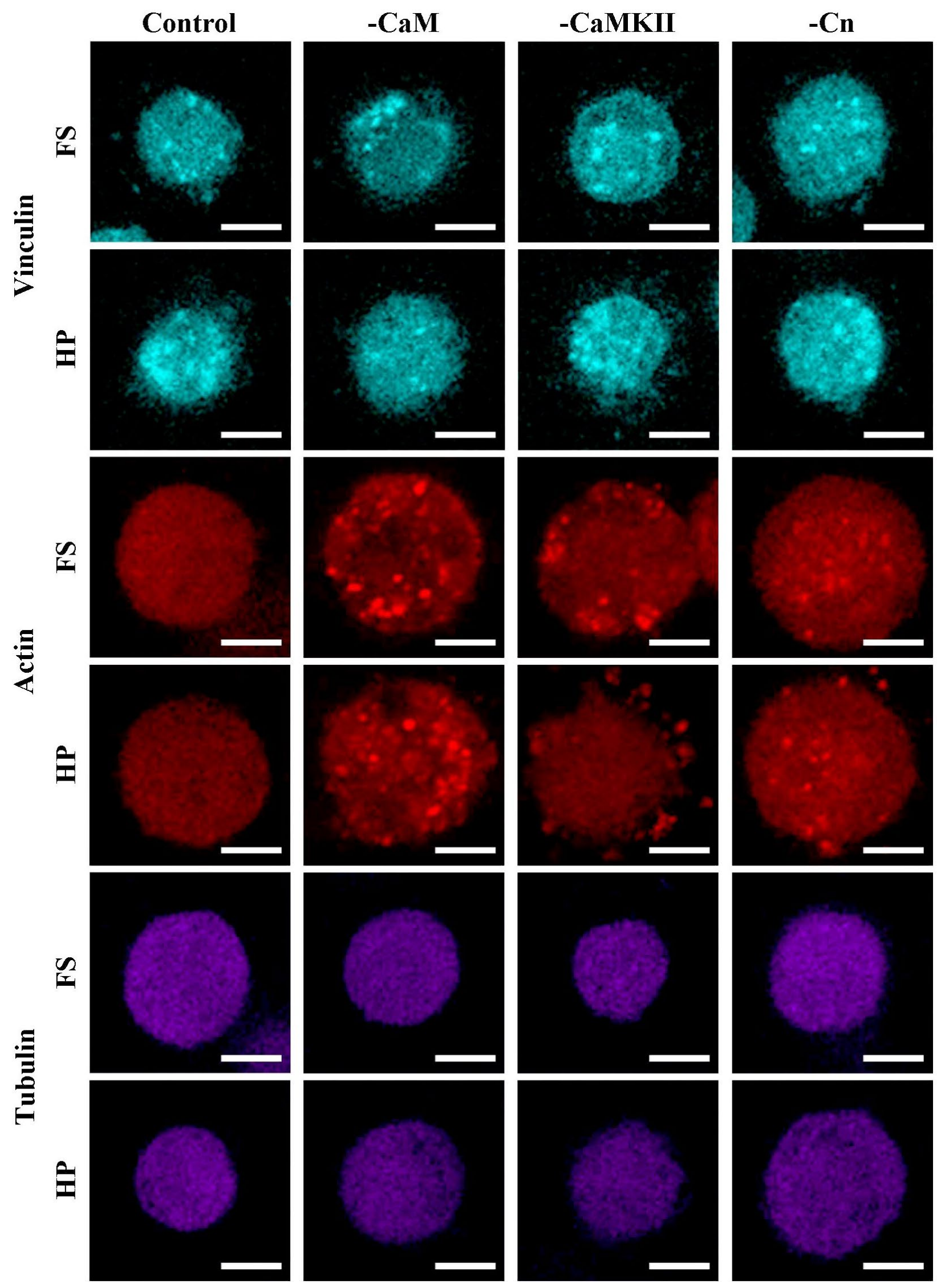

Fig. 9. Representative confocal images of vinculin, actin and tubulin staining of constructs in either the HP or FS groups. Scale bars $=10 \mu \mathrm{m}$. 

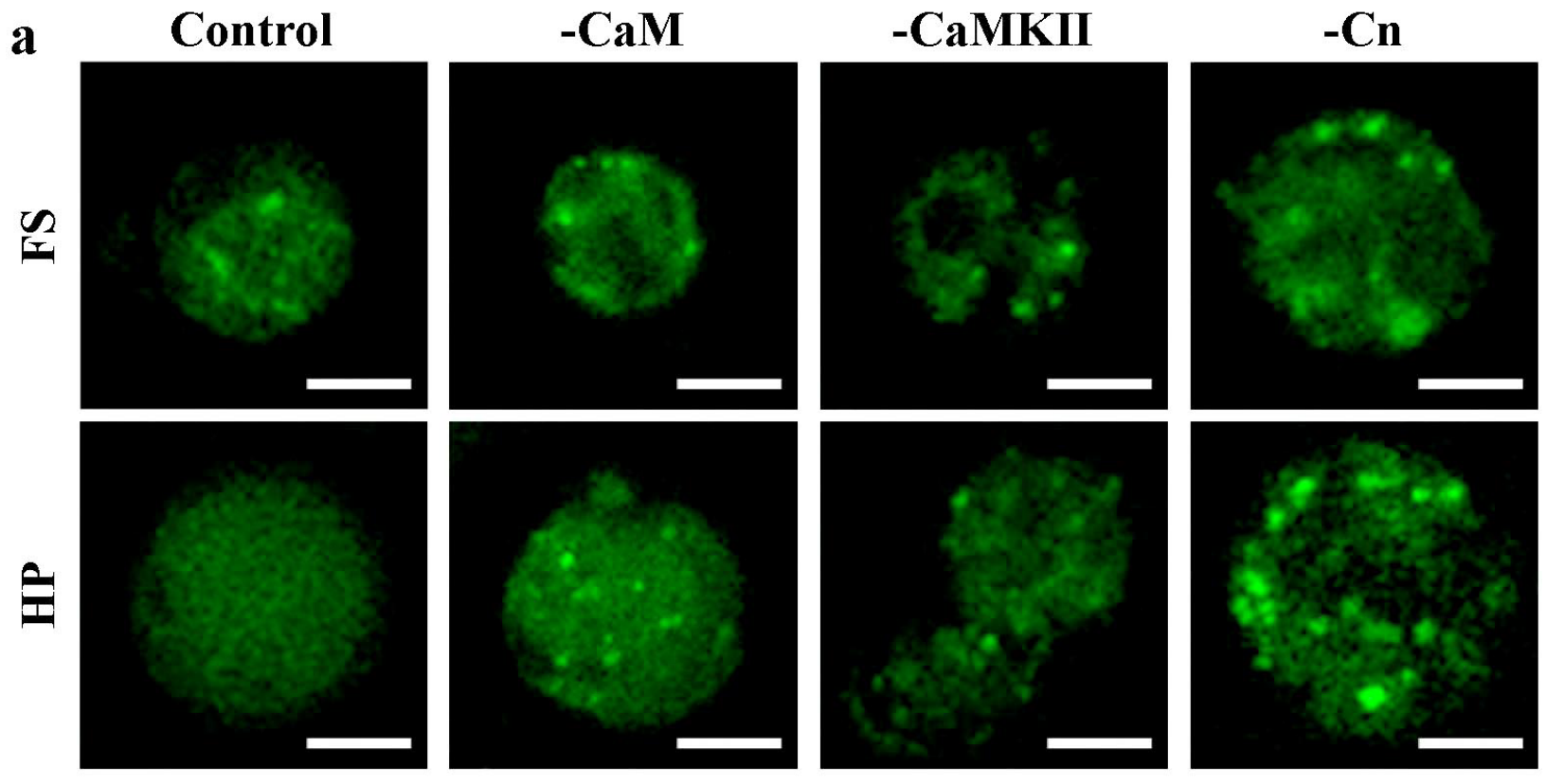

b

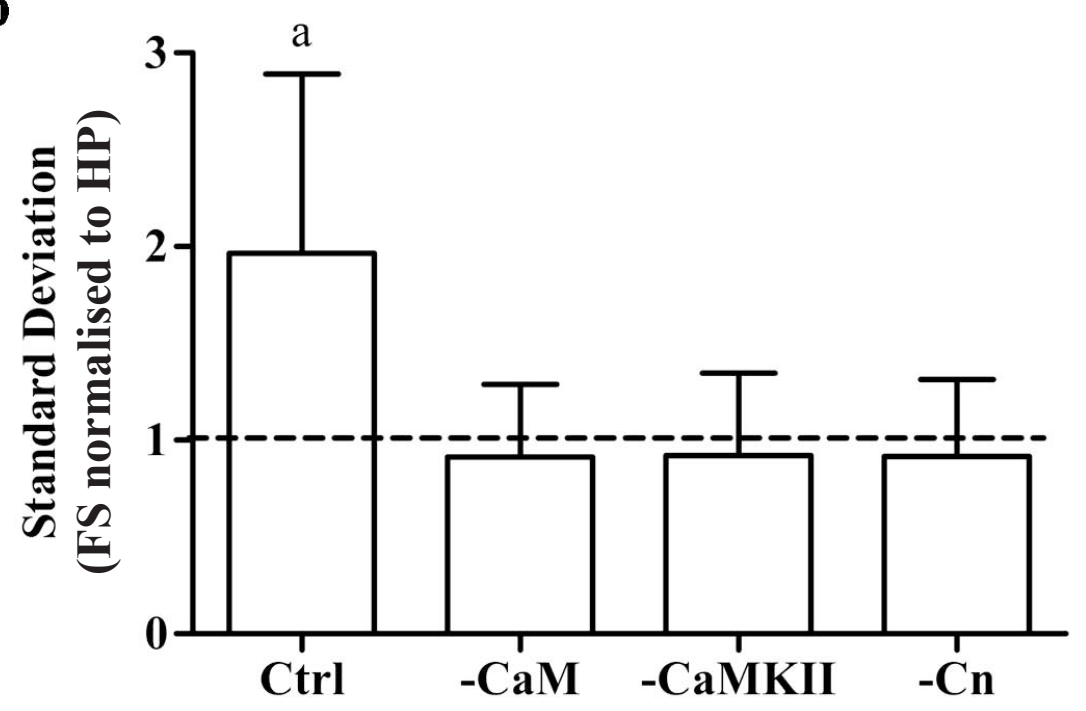

Fig. 10. (a) Representative confocal images of vimentin in constructs in either the HP or FS groups. (b) Semiquantitative analysis using custom MATLAB code to determine differences in vimentin structures in FS constructs normalised to those exposed to HP. Scale bars $=10 \mu \mathrm{m}$. a: $p \leq 0.05$, relative to HP condition.

mechanosensitive groups (Control and -SACCs), while retaining a punctate structure in the other groups (Fig. 6a). Semi-quantitative analysis of vimentin architecture verified this observation, as there was only a significant difference in vimentin architecture with loading in the mechanosensitive groups (Fig. 6b). A $15 \%$ decrease in the number of punctate cells was observed after exposure to HP in the control group.

\section{CaM, CaMKII and Cn may all regulate the} mechanotransduction of HP

In the second experiment, DNA and sGAG/DNA values were also assessed in free-swelling constructs exposed to inhibitors of the downstream calcium targets CaM, CaMKII and $\mathrm{Cn}$. While inhibiting CaMKII led to a significant increase in DNA, none of the inhibitors had a significant effect on the chondrogenic state of the MSCs (Fig. 7). Inhibition of $\mathrm{CaM}$, CaMKII and $\mathrm{Cn}$ all led to a suppression of the beneficial effect of HP on sGAG accumulation (Fig. 8a). Similar to the first experiment, collagen type II accumulation was increased in the control group, but inhibition of CaM, CaMKII and $\mathrm{Cn}$ abrogated this response (Fig. 8b).

CaM, CaMKII and $\mathrm{Cn}$ may be required for changes in vimentin architecture in response to $\mathrm{HP}$

No changes in focal adhesion formation or tubulin architecture were observed with application of either HP or downstream calcium target inhibitors, with all groups retaining punctate focal adhesion formations and diffuse tubulin staining. However, all three inhibitors led to a punctate actin structure that was not affected by application of HP (Fig. 9). As above, MSCs demonstrated a punctate vimentin structure that became more diffuse in response to loading in the control group. However, inhibition of CaM, $\mathrm{CaMKII}$ and $\mathrm{Cn}$ all abrogated the effect of HP on vimentin 
architecture (Fig. 10a). Semi-quantitative analysis of the vimentin structure further verified that inhibition of CaM, CaMKII and $\mathrm{Cn}$ block the change in vimentin structure in response to HP (Fig. 10b).

\section{Discussion}

Similar to previous studies examining other loading modalities such as tension, compression, fluid flow, and osmotic pressure (Campbell et al., 2008; Chao et al., 2006; Guilak et al., 1999; McMahon et al., 2008; Mobasheri et al., 2002; Pingguan-Murphy et al., 2006; Riddle et al., 2006; Roberts et al., 2001; Valhmu and Raia, 2002; Yellowley et al., 1997), $\mathrm{Ca}^{++}$signalling appeared to be necessary for the mechanotransduction of HP in MSCs. This was evidenced by the lack of a response to the mechanical load when intracellular calcium was chelated $\left(-\mathrm{Ca}^{++}\right)$. Mechanotransduction of HP has been proposed to differ from other mechanical loads due to the fact that HP generates a state of stress with little deformation (Elder and Athanasiou, 2009), and indeed this was observed in the mechanism by which $\mathrm{Ca}^{++}$signalling was initiated. Stretchactivated calcium channels (SACCs) play a key role in the mechanoresponse of MSCs to tension, compression, and fluid flow (McMahon et al., 2008; Mobasheri et al., 2002; Roberts et al., 2001; Yellowley et al., 1997); yet, in the current study, their inhibition did not suppress the mechanoresponse of the MSCs to cyclic HP. These results suggest that the mechanotransductive pathways utilised by MSCs in response to HP are distinct from those used to sense and respond to other loading modalities.

Although inhibition of SACCs did not alter the mechanoresponse of MSCs to cyclic HP in the current study, calcium flux through these channels has been observed in response to static HP loading. Mizuno (2005) utilised X-rhod-1 AM and a live-cell imaging bioreactor to measure $\mathrm{Ca}^{++}$concentrations in chondrocytes exposed to $0.5 \mathrm{MPa}$ static HP. Blocking SACCs decreased $\mathrm{Ca}^{++}$mobility and inhibition of VGCCs had no effect on $\mathrm{Ca}^{++}$mobility in response to this static load. In a separate study, cyclic HP had been shown to increase proteoglycan synthesis, while static HP had no effect (Jortikka et al., 2000). Therefore, the differences between Mizuno's observations and those of the current study may be explained by a differential response of MSCs to static versus cyclic HP. Similarly, inhibition of SACCs blocked $\mathrm{Ca}^{++}$mobility and early osteogenic markers in response to static fluid flow (Chen et al., 2000; Hung et al., 1996b; Yellowley et al., 1997); however, inhibition of SACCs did not affect $\mathrm{Ca}^{++}$mobility or osteopontin gene expression in response to oscillatory fluid flow (You et al., 2001). Together, these data suggest that in some cases, SACCs may be more sensitive to static stimuli than oscillatory ones.

In the current study, inhibition of VGCCs and SERCS both appeared to inhibit the chondrogenic response of MSCs to HP. These results suggest that $\mathrm{Ca}^{++}$could potentially enter through VGCCs and subsequently activate calcium-induced calcium release from SERCS. Both VGCCs and SERCS have been shown to be involved in the mechanotransduction of extrinsic mechanical loads, such as fluid flow and compression (Riddle et al., 2006; Shakibaei and Mobasheri, 2003; Valhmu and Raia, 2002). Therefore, although the mechanotransductive pathways involved in the response to HP are distinct from other loading modalities, there appear to be some overlapping principles. Compression of cartilage in the joint pressurises the fluid phase of cartilage and generates HP. Therefore, the fact that studies utilising compression and HP appear to have overlapping mechanotransductive principles could be due to the fact that compressive loading generates a state of HP as well.

Once $\mathrm{Ca}^{++}$enters the cell, secondary messengers are commonly utilised to translate the signal into changes in gene expression. $\mathrm{Ca}^{++}$binds to $\mathrm{CaM}$, inducing a conformational change that allows it to bind to CaMKII and $\mathrm{Cn}$. CaM, CaMKII and $\mathrm{Cn}$ are all proposed to regulate the mechanotransduction of extrinsic loads (Valhmu and Raia, 2002). Compressive loading of bovine articular cartilage explants led to a 2-4 fold increase in aggrecan expression that was abrogated with the additions of inhibitors of CaM, CaMKII and Cn (Valhmu and Raia, 2002). Similarly, in the current study, inhibition of CaM, CaMKII and $\mathrm{Cn}$ all appeared to suppress the beneficial effects of HP on the chondrogenesis of MSCs. Together, this indicates that $\mathrm{Ca}^{++} /$ CaM binding, and its subsequent interaction with CaMKII and $\mathrm{Cn}$, may be an important mechanotransductive pathway in chondrogenic cells.

Cell-matrix interactions regulate chondrogenesis (Steward et al., 2011), and previously, we have demonstrated that integrin binding is required for the mechanotransduction of HP (Steward et al., 2013a). Integrin binding has been correlated with $\mathrm{Ca}^{++}$signalling in response to several mechanical stimuli (Matthews et al., 2006; Mobasheri et al., 2002; Shakibaei and Mobasheri, 2003; Wright et al., 1997; Wu et al., 1998). Integrins have been found to co-localise with VGCCs (Shakibaei and Mobasheri, 2003), and inhibition of integrin binding has been found to decrease $\mathrm{Ca}^{++}$mobility (Wright et al., 1997; Wu et al., 1998). Vinculin staining was not altered with either the application of HP or pharmacological inhibitors, suggesting that any differences observed in response to loading were not due to alterations in integrin binding or focal adhesion formation following the application of such stimuli. The cytoskeleton has been demonstrated to be involved in the mechanotransduction of many different mechanical stimuli and has also been associated with $\mathrm{Ca}^{++}$signalling (Arnsdorf et al., 2009; Chen et al., 2000; Erickson et al., 2003; Formigli et al., 2007; Sadoshima et al., 1992). None of the inhibitors of $\mathrm{Ca}^{++}$mobility affected actin, vimentin, or tubulin organisation; however, the inhibitors of CaM, CaMKII and $\mathrm{Cn}$ all led to a more punctate actin structure. While this could potentially alter the mechanoresponse of the MSCs to HP, a previous study indicated that complete disruption of the actin structure did not influence the mechanotransduction of HP (Shim et al., 2008). Therefore, it seems unlikely that the alterations in actin structure observed in the presence of inhibitors of CaM, CaMKII and $\mathrm{Cn}$ influenced the chondrogenic response of MSCs to $\mathrm{HP}$.

Previously, we demonstrated a novel role for vimentin in the chondrogenic response of MSCs to HP, as vimentin 
staining transitioned from a punctate appearance in freeswelling conditions to a more diffuse organisation when exposed to HP in a percentage of the cells (Steward et al., 2013a). In the current experiment, vimentin organisation was more likely to be punctate in all of the free-swelling conditions, including in the controls and in the specimens exposed to the pharmacological inhibitors. Similar to the previous experiment, vimentin staining became more diffuse when the MSCs were exposed to $\mathrm{HP}$ in the mechanoresponsive groups (Ctrl and -SACCs). However, vimentin remained more punctate with loading in the -Ca ${ }^{++}$, -VGCCs, -SERCS, -CaM, -CaMKII and -Cn groups. Overall, this might suggest that $\mathrm{Ca}^{++}$mobility and associated targets act upstream of changes to vimentin structure. On the other hand, inhibition of $\mathrm{Ca}^{++}$signalling may abrogate the chondrogenic mechanoresponse to HP via a different mechanism that in turn affects the vimentin structure. Overall, this suggests that vimentin reorganisation is integrally correlated to the chondrogenic response of MSCs to HP, and that this reorganisation may be calcium-dependent.

Based on a visual determination of the number of loaded and unloaded cells that had punctate or diffuse vimentin organisation, approximately $15 \%$ of control cells (cells not exposed to any inhibitors) responded to the application of HP with cytoskeletal reorganisation. As vimentin reorganisation was only observed in the mechanoresponsive groups, this $15 \%$ of cells may represent a mechanosensitive subpopulation of the heterogeneous MSCs. Chondrocytes have also been observed to have subpopulations of mechanosensitive cells, as previous studies found that, on average, 20-60\% of chondrocytes embedded in agarose expressed $\mathrm{Ca}^{++}$transients in response to dynamic compression (Pingguan-Murphy et al., 2005; Roberts et al., 2001). Additionally, previous experiments comparing DNA values after 3 weeks to their initial day 0 values suggested an average loss of $10 \%$ of cell number during the culture period; the actual number of cells that did not survive may be greater, as some could have been replaced by proliferating cells. By comparing the number of potentially mechanosensitive cells with the number of cells that do not survive culture, we cannot rule out the possibility that the pharmacological inhibitors used in the current study selected against the mechanoresponsive cells while allowing other cells to survive or proliferate, rather than inhibiting calcium signalling. If this were the case, $\mathrm{Ca}^{++}$inhibitors would not be an appropriate tool to determine the mechanotransduction pathways of chondrogenic MSCs in agarose. In order to be certain of the effect of the inhibitors on the heterogeneous MSC population, a flow cytometry analysis would be required to determine whether a particular phenotype had a lower viability in the presence of inhibitors. However, the markers that would represent mechanoresponsive cells are currently unknown. Furthermore, the possibility that the inhibitors used in the current study would all target the same mechanoresponsive cell population without significantly altering the final DNA and sGAG concentrations in the FS constructs seems unlikely due to the number and variety of inhibitors that eliminated the chondrogenic response to HP. Although an in-depth analysis of the sub-populations of MSCs could yield important findings on the characteristics of mechanoresponsive MSCs, the lack of a consensus in the field on the specific markers of interest limits the utility of this approach.

While VGCCs seem to be critical for a chondrogenic response to HP, the mechanism triggering these channels is unclear. One possibility is that purinergic signalling is acting to trigger the VGCCs. In the purinergic mechanotransduction pathway, MSCs release ATP in response to mechanical loading, and this extracellular ATP in turn induces P-receptors to increase the intracellular $\mathrm{Ca}^{++}$concentration by either direct or indirect methods. The increased intracellular $\mathrm{Ca}^{++}$depolarises the membrane, leading to activation of VGCCs (Bodin and Burnstock, 2001; Pingguan-Murphy and Knight, 2008). Purinergic signalling has been implicated in the mechanotransduction of fluid flow and compression (Graff et al., 2000; PingguanMurphy et al., 2006), yet no studies have investigated its potential role in the mechanotransduction of HP. Alternatively, $\mathrm{HP}$ has been shown to inhibit the $\mathrm{Na} / \mathrm{K}$ pump, $\mathrm{Na} / \mathrm{K} / 2 \mathrm{Cl}$ pump, and enhance the $\mathrm{Na} / \mathrm{H}$ pump (Browning et al., 1999; Elder and Athanasiou, 2009; Hall, 1999). By altering the concentrations of these other ions, VGCCs could potentially be activated. Finally, although HP generates a state of little deformation, it has been proposed that ion channels may contain compressible void spaces that, when exposed to HP, may lead to conformational changes in these proteins and subsequently alter ion mobility (Elder and Athanasiou, 2009; Kornblatt and Kornblatt, 2002).

Overall, we have demonstrated that $\mathrm{Ca}^{++}$signalling may play a critical role in the chondrogenic response of MSCs exposed to HP. The signalling pathway utilised by MSCs appears to involve VGCCs, SERCS, CaM, CaMKII and Cn. SACCs do not appear to play a role in the mechanotransduction of HP, suggesting that the mechanotransductive pathways utilised in response to cyclic HP are distinct from other loading modalities. Vimentin reorganisation in response to HP appears to be $\mathrm{Ca}^{++}$signalling dependent and possibly plays a key role in the chondrogenic response of MSCs to HP. Finally, further research is needed to fully understand the mechanisms by which $\mathrm{HP}$ alters $\mathrm{Ca}^{++}$mobility.

\section{Acknowledgements}

This study was supported by a Naughton Graduate Fellowship and the National Science Foundation under Grant No. 1335007 (BMMB/CMMI). We wish to confirm that there are no known conflicts of interest associated with this publication and there has been no significant financial support for this work that could have influenced its outcome. 


\section{References}

Angele P, Yoo JU, Smith C, Mansour J, Jepsen KJ, Nerlich M, Johnstone B (2003) Cyclic hydrostatic pressure enhances the chondrogenic phenotype of human mesenchymal progenitor cells differentiated in vitro. J Orthop Res 21: 451-457.

Arnsdorf EJ, Tummala P, Kwon RY, Jacobs CR (2009) Mechanically induced osteogenic differentiation - the role of RhoA, ROCKII and cytoskeletal dynamics. J Cell Sci 122: 546-553.

Bodin P, Burnstock G (2001) Purinergic signalling: ATP release. Neurochem Res 26: 959-969.

Browning JA, Walker RE, Hall AC, Wilkins RJ (1999) Modulation of $\mathrm{Na}[\sup +] \times \mathrm{H}[$ sup +$]$ exchange by hydrostatic pressure in isolated bovine articular chondrocytes. Acta Physiol Scand 166: 39-45.

Browning JA, Saunders K, Urban JPG, Wilkins RJ (2004) The influence and interactions of hydrostatic and osmotic pressures on the intracellular milieu of chondrocytes. Biorheology 41: 299-308.

Campbell J, Bader D, Lee D (2008) Mechanical loading modulates intracellular calcium signaling in human mesenchymal stem cells. J Appl Biomater Biomech 6: 9-15.

Carroll SF, Buckley CT, Kelly DJ (2014) Cyclic hydrostatic pressure promotes a stable cartilage phenotype and enhances the functional development of cartilaginous grafts engineered using multipotent stromal cells isolated from bone marrow and infrapatellar fat pad. J Biomech 47: 2115-2121.

Catterall WA (2011) Voltage-gated calcium channels. Cold Spring Harb Perspect Biol 3: a003947.

Chao PG, West AC, Hung CT (2006) Chondrocyte intracellular calcium, cytoskeletal organization, and gene expression responses to dynamic osmotic loading. Am J Physiol Cell Physiol 291: C718-C725.

Chen NX, Ryder KD, Pavalko FM, Turner CH, Burr DB, Qiu J, Duncan RL (2000) Ca2+ regulates fluid shearinduced cytoskeletal reorganization and gene expression in osteoblasts. Am J Physiol Cell Physiol 278: C989-C997.

Discher DE, Mooney DJ, Zandstra PW (2009) Growth factors, matrices, and forces combine and control stem cells. Science 324: 1673-1677.

Elder BD, Athanasiou KA (2009) Hydrostatic pressure in articular cartilage tissue engineering: from chondrocytes to tissue regeneration. Tissue Eng Part B Rev 15: 43-53.

Erickson GR, Northrup DL, Guilak F (2003) Hypo-osmotic stress induces calcium-dependent actin reorganization in articular chondrocytes. Osteoarthritis Cartilage 11: 187-197.

Fodor J, Matta C, Oláh T, Juhász T, Takács R, Tóth A, Dienes B, Csernoch L, Zákány R (2013) Store-operated calcium entry and calcium influx via voltage-operated calcium channels regulate intracellular calcium oscillations in chondrogenic cells. Cell Calcium 54: 1-16.

Formigli L, Meacci E, Sassoli C, Squecco R, Nosi D, Chellini F, Naro F, Francini F, Zecchi-Orlandini S (2007) Cytoskeleton/stretch-activated ion channel interaction regulates myogenic differentiation of skeletal myoblasts. J Cell Physiol 211: 296-306.
Graff RD, Lazarowski ER, Banes AJ, Lee GM (2000) ATP release by mechanically loaded porcine chondrons in pellet culture. Arthritis Rheum 43: 1571-1579.

Guilak F, Zell RA, Erickson GR, Grande DA, Rubin CT, McLeod KJ, Donahue HJ (1999) Mechanically induced calcium waves in articular chondrocytes are inhibited by gadolinium and amiloride. J Orthop Res 17: 421-429.

Hall AC (1999) Differential effects of hydrostatic pressure on cation transport pathways of isolated articular chondrocytes. J Cell Physiol 178: 197-204.

Hung CT, Allen FD, Pollack SR, Brighton CT (1996a) Intracellular $\mathrm{Ca} 2+$ stores and extracellular $\mathrm{Ca} 2+$ are required in the real-time $\mathrm{Ca} 2+$ response of bone cells experiencing fluid flow. J Biomech 29: 1411-1417.

Hung CT, Allen FD, Pollack SR, Brighton CT (1996b) What is the role of the convective current density in the real-time calcium response of cultured bone cells to fluid flow? J Biomech 29: 1403-1409.

Jortikka MO, Parkkinen JJ, Inkinen RI, Kärner J, Järveläinen HT, Nelimarkka LO, Tammi MI, Lammi MJ (2000) The role of microtubules in the regulation of proteoglycan synthesis in chondrocytes under hydrostatic pressure. Arch Biochem Biophys 374: 172-180.

Kelly DJ, Jacobs CR (2010) The role of mechanical signals in regulating chondrogenesis and osteogenesis of mesenchymal stem cells. Birth Defect Res C 90: 75-85.

Kornblatt JA, Kornblatt MJ (2002) The effects of osmotic and hydrostatic pressures on macromolecular systems. Biochim Biophys Acta 1595: 30-47.

Lee HS, Millward-Sadler SJ, Wright MO, Nuki G, Salter DM (2000) Integrin and mechanosensitive ion channel-dependent tyrosine phosphorylation of focal adhesion proteins and $\beta$-catenin in human articular chondrocytes after mechanical stimulation. J Bone Miner Res 15: 1501-1509.

Lennon DP, Caplan AI (2006) Isolation of human marrow-derived mesenchymal stem cells. Exp Hematol 34: 1604-1605.

Luo Z-J, Seedhom BB (2007) Light and low-frequency pulsatile hydrostatic pressure enhances extracellular matrix formation by bone marrow mesenchymal cells: An in-vitro study with special reference to cartilage repair. Proc Inst Mech Eng H 221: 499-507.

Matthews BD, Overby DR, Mannix R, Ingber DE (2006) Cellular adaptation to mechanical stress: role of integrins, Rho, cytoskeletal tension and mechanosensitive ion channels. J Cell Sci 119: 508-518.

McBeath R, Pirone DM, Nelson CM, Bhadriraju K, Chen CS (2004) Cell shape, cytoskeletal tension, and RhoA regulate stem cell lineage commitment. Dev Cell 6: 483-495.

McMahon LA, Campbell VA, Prendergast PJ (2008) Involvement of stretch-activated ion channels in strainregulated glycosaminoglycan synthesis in mesenchymal stem cell-seeded 3D scaffolds. J Biomech 41: 2055-2059.

Meyer EG, Buckley CT, Steward AJ, Kelly DJ (2011) The effect of cyclic hydrostatic pressure on the functional development of cartilaginous tissues engineered using bone marrow derived mesenchymal stem cells. J Mech Behav Biomed Mater 4: 1257-1265. 
Miyanishi K, Trindade MCD, Lindsey DP, Beaupré GS, Carter DR, Goodman SB, Schurman DJ, Smith RL (2006a) Effects of hydrostatic pressure and transforming growth factor-beta 3 on adult human mesenchymal stem cell chondrogenesis in vitro. Tissue Eng. 12: 1419-1428.

Miyanishi K, Trindade MCD, Lindsey DP, Beaupré GS, Carter DR, Goodman SB, Schurman DJ, Smith RL (2006b) Dose- and time-dependent effects of cyclic hydrostatic pressure on transforming growth factor-beta3-induced chondrogenesis by adult human mesenchymal stem cells in vitro. Tissue Eng 12: 2253-2262.

Mizuno S (2005) A novel method for assessing effects of hydrostatic fluid pressure on intracellular calcium: a study with bovine articular chondrocytes. Am J Physiol Cell Physiol 288: C329-C337.

Mobasheri A, Carter SD, Martín-Vasallo P, Shakibaei M (2002) Integrins and stretch activated ion channels; putative components of functional cell surface mechanoreceptors in articular chondrocytes. Cell Biol Int 26: 1-18.

Ogawa R, Mizuno S, Murphy GF, Orgill DP (2009) The effect of hydrostatic pressure on three-dimensional chondroinduction of human adipose-derived stem cells. Tissue Eng Part A 15: 2937-2945.

Park S, Krishnan R, Nicoll SB, Ateshian GA (2003) Cartilage interstitial fluid load support in unconfined compression. J Biomech 36: 1785-1796.

Pingguan-Murphy B, Knight MM (2008) Mechanosensitive purinergic calcium signalling in articular chondrocytes. In: Kamkin A, Kiseleva I (eds) Mechanosensitive Ion Channels, Springer, New York, chapter 10, pp 235-251.

Pingguan-Murphy B, Lee DA, Bader DL, Knight MM (2005) Activation of chondrocytes calcium signalling by dynamic compression is independent of number of cycles. Arch Biochem Biophys 444: 45-51.

Pingguan-Murphy B, El-Azzeh M, Bader D, Knight M (2006) Cyclic compression of chondrocytes modulates a purinergic calcium signalling pathway in a strain rate- and frequency-dependent manner. J Cell Physiol 209: 389-397.

Riddle RC, Taylor AF, Genetos DC, Donahue HJ (2006) MAP kinase and calcium signaling mediate fluid flow-induced human mesenchymal stem cell proliferation. Am J Physiol Cell Physiol 290: C776-C784.

Roberts SR, Knight MM, Lee DA, Bader DL (2001) Mechanical compression influences intracellular $\mathrm{Ca} 2+$ signaling in chondrocytes seeded in agarose constructs. J Appl Physiol 90: 1385-1391.

Sadoshima J, Takahashi T, Jahn L, Izumo S (1992) Roles of mechano-sensitive ion channels, cytoskeleton, and contractile activity in stretch-induced immediate-early gene expression and hypertrophy of cardiac myocytes. Proc Natl Acad Sci USA 89: 9905-9909.

Shakibaei M, Mobasheri A (2003) Beta1-integrins colocalize with $\mathrm{Na}$, K-ATPase, epithelial sodium channels $(\mathrm{ENaC})$ and voltage activated calcium channels (VACC) in mechanoreceptor complexes of mouse limb-bud chondrocytes. Histol Histopathol 18: 343-351.

Shim JW, Wise DA, Elder SH (2008) Effect of cytoskeletal disruption on mechanotransduction of hydrostatic pressure by C3H10T1/2 murine fibroblasts. Open Orthop J 2: 155-162.
Steward AJ, Liu Y, Wagner DR (2011) Engineering cell attachments to scaffolds in cartilage tissue engineering. JOM 63: 74-82.

Steward AJ, Thorpe SD, Vinardell T, Buckley CT, Wagner DR, Kelly DJ (2012) Cell-matrix interactions regulate mesenchymal stem cell response to hydrostatic pressure. Acta Biomater 8: 2153-2159.

Steward AJ, Wagner DR, Kelly DJ (2013a) The pericellular environment regulates cytoskeletal development and the differentiation of mesenchymal stem cells and determines their response to hydrostatic pressure. Eur Cell Mater 25: 167-178.

Steward AJ, Wagner D, Kelly D (2013b) Exploring the roles of integrin binding and cytoskeletal reorganization during mesenchymal stem cell mechanotransduction in soft and stiff hydrogels subjected to dynamic compression. J Mech Behav Biomed Mater 38 :174-182.

Szabo E, Feng T, Dziak E, Opas M (2009) Cell Adhesion and Spreading Affect Adipogenesis from Embryonic Stem Cells: The Role of Calreticulin. Stem Cells 27: 2092-2102.

Thorpe SD, Buckley CT, Vinardell T, O’Brien FJ, Campbell VA, Kelly DJ (2008) Dynamic compression can inhibit chondrogenesis of mesenchymal stem cells. Biochem Biophys. Res Commun 377: 458-462.

Thorpe SD, Buckley CT, Vinardell T, O'Brien FJ, Campbell VA, Kelly DJ (2010) The response of bone marrow-derived mesenchymal stem cells to dynamic compression following TGF- $\beta 3$ induced chondrogenic differentiation. Ann Biomed Eng 38: 2896-2909.

Thorpe SD, Buckley CT, Steward AJ, Kelly DJ (2012) European Society of Biomechanics S.M. Perren Award 2012: The external mechanical environment can override the influence of local substrate in determining stem cell fate. J Biomech 45: 2483-2492.

Tomita M, Reinhold MI, Molkentin JD, Naski MC (2002) Calcineurin and NFAT4 induce chondrogenesis. J Biol Chem 277: 42214-42218.

Valhmu WB, Raia FJ (2002) myo-Inositol 1,4,5-trisphosphate and $\mathrm{Ca}(2+) /$ calmodulin-dependent factors mediate transduction of compression-induced signals in bovine articular chondrocytes. Biochem J 361: 689-696.

Vinardell T, Rolfe RA, Buckley CT, Meyer EG, Ahearne M, Murphy P, Kelly DJ (2012) Hydrostatic pressure acts to stabilise a chondrogenic phenotype in porcine joint tissue derived stem cells. Eur Cell Mater 23: 121-134.

Wagner DR, Lindsey DP, Li KW, Tummala P, Chandran SE, Smith RL, Longaker MT, Carter DR, Beaupre GS (2008) Hydrostatic pressure enhances chondrogenic differentiation of human bone marrow stromal cells in osteochondrogenic medium. Ann Biomed Eng 36: 813820.

Wong M, Siegrist M, Goodwin K (2003) Cyclic tensile strain and cyclic hydrostatic pressure differentially regulate expression of hypertrophic markers in primary chondrocytes. Bone 33: 685-693.

Wright M, Jobanputra P, Bavington C, Salter DM, Nuki $\mathrm{G}$ (1996) Effects of intermittent pressure-induced strain on the electrophysiology of cultured human chondrocytes: 
evidence for the presence of stretch-activated membrane ion channels. Clin Sci 90: 61-71.

Wright MO, Nishida K, Bavington C, Godolphin JL, Dunne E, Walmsley S, Jobanputra P, Nuki G, Salter DM (1997) Hyperpolarisation of cultured human chondrocytes following cyclical pressure-induced strain: Evidence of a role for $\alpha 5 \beta 1$ integrin as a chondrocyte mechanoreceptor. J Orthop Res 15: 742-747.

Wu X, Mogford JE, Platts SH, Davis GE, Meininger GA, Davis MJ (1998) Modulation of calcium current in arteriolar smooth muscle by $\alpha v \beta 3$ and $\alpha 5 \beta 1$ integrin ligands. J Cell Biol 143: 241-252.

Xu J, Wang W, Clark CC, Brighton CT (2009) Signal transduction in electrically stimulated articular chondrocytes involves translocation of extracellular calcium through voltage-gated channels. Osteoarthritis Cartilage 17: 397-405.

Yellowley CE, Jacobs CR, Li Z, Zhou Z, Donahue HJ (1997) Effects of fluid flow on intracellular calcium in bovine articular chondrocytes. Am J Physiol Cell Physiol 273: C30-C36.

You J, Reilly GC, Zhen X, Yellowley CE, Chen Q, Donahue HJ, Jacobs CR (2001) Osteopontin gene regulation by oscillatory fluid flow via intracellular calcium mobilization and activation of mitogen-activated protein kinase in MC3T3-E1 osteoblasts. J Biol Chem 276: 13365 13371.

\section{Discussion with Reviewers}

Reviewer II: As chondrogenesis of MSCs is being studied, a general question is when would the MSCs be considered "chondrocytes" and would their behaviour to HP be expected to converge with that of mature chondrocytes?

Authors: The question of when MSCs are sufficiently differentiated to the point that they can be considered chondrocytes is a complicated one. While MSCs can obtain many features of chondrocytes, including sGAG and type II collagen production, they also express markers of hypertrophy when cultured in standard chondrogenic conditions. Therefore, despite the similarities, MSCs differentiated to the chondrogenic lineage generally do not exhibit a stable chondrocytic phenotype, though alternate culture conditions such as hypoxia and HP suppress the hypertrophic markers (Carroll et al., 2014; Sheehy et al., 2012; Vinardell et al., 2012). Despite these differences, the chondrogenic response to HP appears to be similar between the cell types. In the two experiments presented in the current study, sGAG/DNA was increased by $23 \%$ and $24 \%$, respectively, in response to HP. Other studies using chondrocyte explants and chondrocyte-seeded scaffolds observed a 17-40\% increase in sulphate incorporation (Hall et al., 1991; Mizuno et al., 2002; Parkkinen et al., 1993) when exposed to various HP protocols. Although it was not investigated directly in the current study, it seems likely that the calcium-dependent mechanisms that are involved in the response of MSCs to HP are similarly involved in the response of chondrocytes, though this would need to be tested for certainty. Furthermore, other cells with similar phenotypes, such as those from the intervertebral disc and meniscus, may also respond to HP through these mechanisms.

Reviewer II: How would you expect the MSC response to applied hydrostatic pressure to change with increasing chondrogenic phenotype? Would their response be similar to chondrocytes undergoing dedifferentiation?

Authors: Because we collected media samples at every media change and quantified their sGAG content, we had the opportunity to study how the chondrogenic response varied over the culture period. Although the data fluctuate significantly between different donors and experiments, one trend that was reliably observed over several experiments was that the largest response to the mechanical load never occurred during the first week of culture. This is consistent with our previous work demonstrating that integrin attachment is required for the mechanotransduction of HP (Steward et al., 2013a), and suggests that at least one week is required for MSCs to develop a sufficient pericellular matrix to transmit the mechanical load. We expect that chondrocytes in agarose would deposit a pericellular matrix more quickly, and therefore may have an earlier response to HP than either MSCs or dedifferentiated chondrocytes.

\section{Additional References}

Hall AC, Urban JPG, Gehl KA (1991) The effects of hydrostatic pressure on matrix synthesis in articular cartilage. J Orthop Res 9: 1-10.

Mizuno S, Tateishi T, Ushida T, Glowacki J (2002) Hydrostatic fluid pressure enhances matrix synthesis and accumulation by bovine chondrocytes in three-dimensional culture. J Cell Physiol 193: 319-327.

Parkkinen JJ, Ikonen J, Lammi MJ, Laakkonen J, Tammi M, Helminen HJ (1993) Effects of cyclic hydrostatic pressure on proteoglycan synthesis in cultured chondrocytes and articular cartilage explants. Arch Biochem Biophys 300: 458-465.

Sheehy EJ, Buckley CT, Kelly DJ (2012) Oxygen tension regulates the osteogenic, chondrogenic and endochondral phenotype of bone marrow derived mesenchymal stem cells. Biochem Biophys Res Commun 417: 305-310. 